\title{
Eliciting Preferences for Health Insurance in Iran Using Discrete Choice Experiment Analysis
}

\author{
Ali Kazemi Karyani ${ }^{12^{*}}{ }^{\mathbb{D}}$, Ali Akbari Sari ${ }^{2}$, Abraha Woldemichael ${ }^{3,2}$
}

\begin{abstract}
Background: The preferences of Iranians concerning the attributes of health insurance benefit packages are not well studied. This study aimed to elicit health insurance preferences among insured people in Iran during 2016.

Methods: A mixed methods study using a discrete choice experiment (DCE) approach was conducted to elicit health insurance preferences on a total sample of 600 insured Iranians residing in Tehran. The final design of the DCE included 8 health insurance attributes. Data were analyzed using conditional logistic regression models.

Results: The final model of this DCE study included 8 attributes, and the findings indicated statistically significant $(P<.001)$ increase in the odds ratio $(\mathrm{OR})$ of choosing health insurance at all levels of cost coverage except for the rehabilitation and para-clinical benefits, where at $70 \%$ cost coverage there was insignificant $(P=.485)$ disutility $(\mathrm{OR}=0.95)$. With the increase in cost coverage level, the probability of choosing health insurance was significantly $(P<.001)$ the highest for the private hospitals' benefits $(\mathrm{OR}=2.82)$ followed by public hospitals' benefits $(\mathrm{OR}=2.02)$ and outpatient benefits $(\mathrm{OR}=1.75)$, and the premium revealed statistically significant $(P<.001)$ disutility $(\mathrm{OR}=0.96)$. Conclusion: Our findings revealed that participants would be willing to choose health insurance plans with higher cost coverage of healthcare services and with lower premiums. However, the demographic characteristics, income, and health status of the insured individuals affected their health insurance preferences. The findings can contribute to the design of better health insurance policies, improve the participation of individuals in health insurance, and increase the insured individuals' utility from the insurance benefits packages.

Keywords: Preferences, Health Insurance, Attributes, Discrete Choice, Iran

Copyright: $\odot 2019$ The Author(s); Published by Kerman University of Medical Sciences. This is an open-access article distributed under the terms of the Creative Commons Attribution License (http://creativecommons.org/licenses/ by/4.0), which permits unrestricted use, distribution, and reproduction in any medium, provided the original work is properly cited.

Citation: Kazemi Karyani A, Akbari Sari A, Woldemichael A. Eliciting preferences for health insurance in Iran using discrete choice experiment analysis. Int J Health Policy Manag. 2019;8(8):488-497. doi:10.15171/ijhpm.2019.29
\end{abstract}

\section{Article History:}

Received: 26 June 2018 Accepted: 8 May 2019 ePublished: 9 June 2019

\section{Key Messages}

Implications for policy makers

- Generally, the participants are willing to choose health insurance plans with higher cost coverage of healthcare services and with lower premiums.

- The private hospitals' benefits followed by the public hospitals' benefits provided the highest utility for all sub-categories of the insured respondents than the other attributes.

- The cost coverage of the dental services, long-term care, and para-clinical and rehabilitation services provided the lower utilities for the participants.

Implications for the public

Evidence concerning health insurance preferences of the insured people is useful for improving and designing better benefits packages. Health insurance with a higher cost coverage of the public and private hospitals' (inpatient) and outpatient services benefits can provide more utility to people. The service users might consider the insurance for the health benefits packages such as dental care as less important. Thus, providing them with the opportunity for more options for basic benefits packages could have increased their utilities.

\section{Introduction}

Health insurance is one of the financing mechanisms in health. Most countries use different ways of health insurance to reduce uncertainty in health expenditures by collecting predictable premiums from members. ${ }^{1}$ Health insurance has a considerably high positive effect on social protection and economic development, especially to vulnerable people such as the poor and rural residents. ${ }^{2}$

Article 29 of the constitution of the Islamic Republic of Iran states that all Iranians should have health insurance coverage. Public participation and revenues collected from the public are among the vital sources of financing the healthcare. Other main financing sources included health insurance payments and out of pocket payments. Generally, the Iranian health system is dominantly an insurance-based system. ${ }^{3}$

There is a mix of public and private health insurance schemes in the Iranian health system. However, the Social Security Insurance Organization (SSIO), and the Health 
Insurance Organization (HIO) formerly called the Medical Insurance Organization are the main ones. The Armed Forces Medical Services Insurance Organization, and the Imdad Committee Health Insurance are also other schemes that cover health insurance for the military and the poor, respectively. ${ }^{3}$ In 2013, the SSIO insured about 39 million people. This figure has increased to more than 42 million people in 2017, out of which about 8 million of them resided in Tehran province. ${ }^{4}$ Again, the HIO has insured another more than 32 million people in $2018 .^{5}$

The healthcare financing challenges and the poor design of the insurance schemes are among the main issues that constrained the successful financial protection and service delivery in Iran. The insurance schemes that are designed based on diseases by ignoring the health, pricing, definition of tariffs, and benefits packages are not evidence-based. ${ }^{6}$ The designing of health insurance schemes should consider peoples' preferences. The discrete choice experiment (DCE) method is a suitable method to assess peoples' health insurance preferences. This method, for example, has been used to generate evidence concerning the Dutch peoples' preferences among the different health insurance plans, ${ }^{7}$ and to elicit the health insurance preferences of different groups of people in Thailand. ${ }^{8,9}$

The demand for health insurance largely depends on its ability to meet the consumer's needs, expectations and preferences. ${ }^{9,10}$ To the best of our knowledge, little evidence is available concerning the health insurance preferences of the Iranians. This study aimed to elicit the health insurance preferences of Iranians residing in Tehran using the DCE method. The findings are of paramount importance inputs for health insurance policy making and to provide people with health insurance benefits packages that incorporate their preferences in the context of Iran and perhaps beyond.

\section{Methods}

Study Area

Iran is one of the middle-income countries with a total population of about 80 million people for the year 2016 and spent about $6.9 \%$ of its gross domestic product (GDP) on health in 2014. ${ }^{11}$ The health system has both the private and public sectors. The public sector is responsible for the provision of primary, secondary and tertiary healthcare services, while the private sector provides secondary and tertiary services. ${ }^{12}$ Most of the secondary and tertiary healthcare services are under the coverage of health insurance. However, the services users have to pay coinsurance payments at the point of service delivery. These payments are higher in the private sector because the tariff is higher in the private sector than in the public one. The individuals with no health insurance coverage should pay all the charges, especially when they obtain the services from the private sector. ${ }^{13}$

About three-fourth (74.4\%) of the Iranians are urban residents. ${ }^{4}$ In 2010 , around $16 \%$ of the urban population did not have any health insurance coverage. ${ }^{14}$ In April 2014, the health sector evolution plan of Iran introduced a health insurance scheme to remove the financial barriers of access to healthcare services. This plan provided health insurance coverage for people who have no health insurance coverage by the HIO through the government's financial support. For those who cannot afford the cost of health insurance, the premium was free. This intervention increased the coverage of health insurance in the country. ${ }^{15}$ The compulsory health insurance is the means to cover the rural residents and almost do not pay any premium. ${ }^{16}$ This study focused on the insured Iranians residing in Tehran, the capital of Iran, during 2016.

\section{Experimental Design}

We applied a mixed methods study using a DCE to elicit health insurance preferences among the insured Iranians living in Tehran. This study involved 4 stages of the DCE method. ${ }^{17-19}$ Initially, we determined the attributes and attribute-levels from a list obtained by narrative reviews and interviews of nine experts. Reviewing literature, and interviewing of groups such as experts, and study population or a mix of these methods is a regular practice to determining the attributes in DCE studies. Thus, we performed review of literature and experts' interview to extract the preliminary list of health insurance attributes. Then, 36 experts assessed the list and identified 8 eligible ones. The details of the attributes and attributeslevels are available elsewhere. ${ }^{20}$ The D-efficiency criteria have been used to design the choice set and select the most efficient attributes to be included in the final experimental design. ${ }^{19}$ The final design contained 24 choice set divided into 3 blocks. Each block had 8 choice set which again consisted of plans A and B. The experimental design of the choice set was performed using the SAS version 9.1.

We designed a questionnaire that consisted of 3 sections: the description of the research and informed consent, the socio-economic and demographic characteristics of the participants, and 3 blocks of 8 choice set. Therefore, we developed 3 versions of the questionnaire that were different only in the choice set (blocks). The participants were explained about the included attributes before proceeding the tasks, and the dominant choice set was used to test for consistency of the questions and to warm up the participants. In this phase, we excluded the participants who missed the correct answer to the dominant choice set. We used the experts' opinion to validate and piloted the questionnaire. Each block of the choice set was pilot tested on 15 insured participants from the study area to ensuring the reliability and internal consistency of the tool. The pilot data were excluded from the analysis. Two trained data collectors obtained the data for the final analysis using an interview method. The research team has performed regular supervision to ensure the quality of the collected data. The attributes and attribute-levels of the health insurance in Iran and the choice set included in the analysis of our study are shown in Table 1 and Table 2, respectively.

\section{Sample Size}

Determining the sample size of the DCE study is complex. Some suggest at least 30 participants for each subgroup such as age, gender, etc. ${ }^{17}$ Others recommend a threshold of $1000,{ }^{16}$ and yet other researchers suggested a minimum of 500 to ensure the precision of the findings. Our study considered a threshold of 1000 and the sample size was calculated using the 
Table 1. Attributes and Attribute-Levels of the Health Insurance in Iran

\begin{tabular}{ll}
\hline Attributes & Levels \\
\hline Public hospitals benefits & Coverage of $60 / 90 \%$ of costs \\
\hline Private hospitals benefits & Coverage of $50 / 70 / 90 \%$ of costs \\
Outpatient benefits & Coverage of $50 / 70 / 90 \%$ of costs \\
Dental care coverage benefits & Coverage of $40 / 70 \%$ of costs \\
Rehabilitation and para-clinical benefits & Coverage of $50 / 70 / 90 \%$ of costs \\
Long-term care benefits & Coverage of $50 / 70 / 90 \%$ of costs \\
Medical devices benefits & Coverage of $60 / 90 \%$ of costs \\
Premium & $250000 / 350000 / 450000$ Rials \\
\hline
\end{tabular}

Table 2. One of the Choice Set Included in the Study

\begin{tabular}{|c|c|c|}
\hline Attributes & Plan A & Plan B \\
\hline Public hospitals benefits (cost coverage) & $60 \%$ & $90 \%$ \\
\hline Private hospitals benefits (cost coverage) & $90 \%$ & $50 \%$ \\
\hline Outpatient benefits (cost coverage) & $70 \%$ & $90 \%$ \\
\hline Dental coverage (cost coverage) & $40 \%$ & $40 \%$ \\
\hline $\begin{array}{l}\text { Rehabilitation and para-clinical benefits (cost } \\
\text { coverage) }\end{array}$ & $70 \%$ & $70 \%$ \\
\hline Long-term care (cost coverage) & $50 \%$ & $70 \%$ \\
\hline Benefits for medical devices (cost coverage) & $60 \%$ & $90 \%$ \\
\hline Premium (IRRs) & 450000 & 350000 \\
\hline \multicolumn{3}{|c|}{$\begin{array}{l}\text { Which of the health insurance plans would you like to choose (Please tick } \\
\text { one box only)? }\end{array}$} \\
\hline
\end{tabular}

following formula ${ }^{21}$ :

$S=\frac{n t a}{c}$

Where $S$ represents the sample size, $n$ is the total number of respondents, $t$ is the total number of choice sets in the questionnaire, $a$ is the number of alternatives in the choice sets, and $c$ is the highest number of levels in the final attributes. The sample size in this study was 600 participants.

\section{Sampling Technique}

Initially, we grouped the 22 municipalities in Tehran into 5 homogeneous clusters. Then, we selected one municipality from each cluster and a branch each from the SSIO and the HIO operating in that municipality randomly. Finally, we applied the proportionate allocation to population size technique to determine the sample size needed from each agency and selected the insured individuals using a systematic random sampling technique.

\section{Data Analysis}

The random utility theory was the basis for the analysis of the DCEs data. Accordingly, consider that a person should choose between 2 alternatives A or B, and chose A. This indicates that alternative A provides more utility to the person than alternative $\mathrm{B}$, and can be mathematically expressed as follows. $^{22}$

$$
U(A, C)>U(B, C)
$$

Where $\mathrm{U}$ is the utility derived from each alternative $\mathrm{A}$ and $\mathrm{B}$, and $\mathrm{C}$ is a personal attribute which becomes effective upon choosing the alternative. As $\mathrm{C}$ is a common element both sides of equation 2, alternatively equation 2 can be expressed as follow:

$V(A-B)=U(A, C)-U(B, C)$

Where $\mathrm{V}$ is indirect utility obtained from the alternative A compared with alternative B. The fitted utility function is expressed using a linear equation as follows:

$$
\begin{aligned}
& V=\beta_{1} \text { Pubh }+\beta_{2} \text { Prih }+\beta_{3} \text { Outp }+\beta_{4} \text { Dent }+\beta_{5} R e p+\beta_{6} L t+\beta_{7} M d \\
& +\beta_{8} \text { Prem }+\varepsilon
\end{aligned}
$$

Where $\beta_{1}$ to $\beta_{8}$ are the coefficients of the benefit packages, and the attributes: Pubh (public hospitals benefits), Prich (private hospitals benefits), Outp (Outpatient benefits), Dent (dental coverage), Rep (rehabilitation and Para-clinical benefits), Lt (long-term care), Md (benefits for medical devices), and Prem (Premium) included in the analysis, and $\varepsilon$ is the error term. Assuming that the error terms have Logistic distribution, we applied the conditional logit regression model to analyze the data. ${ }^{23}$ This model assumes that the choices made are independent of irrelevant alternatives (IIA) which may be restrictive. Meanwhile, it is more useful to estimate the utility obtained from an attribute than using the more complicated models such as the nested logit and mixed logit models. ${ }^{24}$ The positive (negative) $\beta$ coefficient indicates an individual's utility (disutility) from the use of the chosen attribute. The McFadden $\mathrm{R}^{2}$ and $\chi^{2}$ tests were used to examine the goodness of fit of the models. We used the statistical software packages SAS 9.1 and Stata 13 (StataCorp, College Station, TX, USA) to perform the analysis.

\section{Results}

Attributes and Levels

The benefits from the public hospital services, private hospital services, outpatient services, dental care coverage, rehabilitation and para-clinical services, long-term care, medical devices (eg, Ortez, Protez, etc), and the health insurance premium were the attributes included in the final design. The service cost coverage levels for the private hospital benefits, outpatient benefits, rehabilitation and para-clinical therapy benefits, and long-term care benefits were 50\%, 70\%, and $90 \%$, respectively. The base and service cost coverage levels for the dental care were $40 \%$ and $70 \%$, while for the public hospital benefits and the medical devices benefits the base and levels were $60 \%$ and $90 \%$, respectively. The premium levels were 250 000, 350000 , and 450000 Iranian Rials (IRRs), respectively. Each US dollar was equal to 32000 IRRs in the time of the study. The public hospitals were affiliated to medical universities under the supervision of the Ministry of Health and Medical Education, while the private hospitals provide services and owned by private health sector.

Out of the total 600 study participants, males accounted for 
Table 3. Descriptive Statistics of Insured Study Participants in Tehran, Iran; 2016

\begin{tabular}{|c|c|c|c|c|}
\hline \multirow{2}{*}{ Variables } & & Male & Female & Total \\
\hline & & No. $\left(\%^{\mathrm{a}}\right)$ & No. $\left(\%{ }^{a}\right)$ & No. $\left(\%{ }^{\mathrm{a}}\right)$ \\
\hline \multirow{2}{*}{ Age } & 41 and younger & $175(29.17)$ & $160(26.67)$ & $335(55.83)$ \\
\hline & Older than 41 & $152(25.33)$ & $113(18.83)$ & $265(44.17)$ \\
\hline \multirow{2}{*}{ Education level (years of schooling) } & Low educated $(\leq 12)$ & $188(31.33)$ & $141(23.50)$ & $329(54.83)$ \\
\hline & High educated (>12) & $139(23.17)$ & $132(22.00)$ & $271(45.17)$ \\
\hline \multirow{2}{*}{ Head of household } & Yes & $248(41.33)$ & $52(8.67)$ & $300(50.00)$ \\
\hline & No & 79 (13.17) & $221(36.83)$ & $300(50.00)$ \\
\hline \multirow{3}{*}{ Household income (in million IRRs) } & $\leq 20$ & $156(26.00)$ & $150(25.00)$ & $306(51.00)$ \\
\hline & $21-40$ & $110(18.33)$ & $79(13.17)$ & $189(31.50)$ \\
\hline & $>40$ & $61(10.17)$ & $44(7.33)$ & $105(17.50)$ \\
\hline \multirow{2}{*}{ Type of basic health insurance } & SSIO & $249(41.50)$ & $206(34.33)$ & $455(75.83)$ \\
\hline & Others (HIO, etc) & $78(13.00)$ & $67(11.17)$ & $145(24.17)$ \\
\hline \multirow{2}{*}{ Chronic condition (s) } & Yes & $175(29.17)$ & $163(27.17)$ & $338(56.33)$ \\
\hline & No & $152(25.33)$ & $110(18.33)$ & $262(43.67)$ \\
\hline Overall total & & $327(54.50)$ & $273(45.50)$ & $600(100.00)$ \\
\hline
\end{tabular}

Abbreviations: SSIO, social security insurance organization; $\mathrm{HIO}$, health insurance organization.

a Percentage for all the cells was calculated from total participants (dominator equals to 600).

327 (54.5\%) (Table 3). The mean age was $41.48 \pm \mathrm{SD}=14.67$ years. Those participants with above 12 years of schooling accounted for $45.17 \%$. Furthermore, $36.16 \%$ of the male and $16.50 \%$ of the female participants were employed, while $15.83 \%$ of the overall participants were retired. Again, 76\% and $28 \%$ of the total study participants were male and female household heads, respectively. The monthly income for $41 \%$ of the households was less than twenty million IRRs, while for $31.5 \%$ it was 21 to 40 million IRRs. About $75 \%$ of participants had social security insurance, and $56.33 \%$ of participants had one or more chronic diseases.

\section{Preferences About Health Insurance}

The regression analysis revealed statistically significant $(P \leq .001)$ associations between increasing the cost of coverage levels and the probability of choosing the health insurance for all the attributes except for the $70 \%$ coverage level for the rehabilitation and para-clinical benefit which was insignificant $(P=.485)$. Increasing the cost coverage level from $50 \%$ to $90 \%$ significantly $(P<.001)$ increased the odds of choosing the health insurance for the private hospital benefits more than twice (odds ratio $[\mathrm{OR}]=2.82$ ). Increasing the cost coverage level for the public hospital benefits from $60 \%$ to $90 \%$ also increased the probability of choosing health insurance for the public hospital benefits by about twice (Table 4 ).

\section{Subgroup Analysis}

Preferences by Gender: The findings revealed that both males and females had higher utilities from the inpatient and outpatient benefits than from the other attributes. At $70 \%$

Table 4. Regression Model Eliciting Preferences of Attributes of Health Insurance

\begin{tabular}{|c|c|c|c|c|c|}
\hline Attributes & Cost Coverage & $\beta$ & SE & $P$ Value & OR \\
\hline Public hospitals benefits (base: $60 \%$ ) & $90 \%$ & 0.705 & 0.036 & $<.001$ & 2.023 \\
\hline Private hospitals benefits (base: $50 \%$ ) & $70 \%$ & 0.585 & 0.053 & $<.001$ & 1.795 \\
\hline \multirow{2}{*}{ Outpatient benefits (base: $50 \%$ ) } & $70 \%$ & 0.270 & 0.050 & $<.001$ & 1.310 \\
\hline & $90 \%$ & 0.561 & 0.052 & $<.001$ & 1.753 \\
\hline Dental coverage (base: $40 \%$ ) & $70 \%$ & 0.451 & 0.078 & $<.001$ & 1.570 \\
\hline \multirow{2}{*}{ Rehabilitation and para-clinical benefits (base: $50 \%$ ) } & $70 \%$ & -0.047 & 0.067 & .485 & 0.954 \\
\hline & $90 \%$ & 0.484 & 0.058 & $<.001$ & 1.622 \\
\hline \multirow{2}{*}{ Long-term care benefits (base: $50 \%$ ) } & $70 \%$ & 0.259 & 0.074 & $<.001$ & 1.306 \\
\hline & $90 \%$ & 0.356 & 0.076 & $<.001$ & 1.428 \\
\hline Medical devices benefits (base: $60 \%$ ) & $90 \%$ & 0.209 & 0.057 & $<.001$ & 1.232 \\
\hline Premium (per 10000 IRRs) & - & -0.036 & 0.004 & $<.001$ & 0.965 \\
\hline Observation & 9600 & & & & \\
\hline Log likelihood & -2695 & & & & \\
\hline $\operatorname{LR} \operatorname{chi} 2\left(1^{2}\right)$ & 1263 & & & & \\
\hline Prob > chi2 & $<0.001$ & & & & \\
\hline
\end{tabular}

Abbreviations: SE, standard error; OR, odds ratio. 
cost coverage for the rehabilitation and para-clinical benefits, females had disutility $(\mathrm{OR}=0.86)$, and males had some utility $(\mathrm{OR}=1.04)$. The public hospitals' benefits at $90 \%$ cost coverage provided relatively a higher utility for males than for females (OR: 2.23 vs. 1.81), while females had considerably higher utility from the private hospitals' benefits than males (OR: 3.15 vs. 2.58). Both males and females showed an increase in the utility from the outpatient benefits with an increase in cost coverage (Table 5).

Preferences by age: The cost coverage of the inpatient services resulted in the highest utility for both age groups. The coefficient of the public hospitals' benefits for those whose age was 41 years and younger $(\mathrm{OR}=1.98)$ and for those over the age of 41 years $(\mathrm{OR}=2.10)$ were nearly equal, while the utility from the private hospital benefits at 70\% and $90 \%$ cost coverage were higher for the younger age group.

The younger age group had higher utilities of the outpatient and dental services than their counterpart. In contrast, the older age group's utility level of long-term care benefits was relatively higher (Table 5). At $70 \%$ cost coverage, both age groups had statistically insignificant $(P>.05)$ disutility of the rehabilitation and para-clinical benefits. However, the older and younger age groups showed about an equal level of disutility of the premium ( $\mathrm{OR}=0.97$ vs. 0.96$)$. At $70 \%$ cost coverage, all the attributes except for the rehabilitation and para-clinical benefits were statistically significant $(P<.05)$.

Preferences by educational level: The lower educated group had relatively a higher utility of the public hospitals' benefits than the higher educated group $(\mathrm{OR}=2.15$ vs. 1.88$)$. The utility level from all the attributes except the long-term care was higher for the higher educated group than for the lower educated one (Table 5). Both groups had higher differences in the level of utilities from the private hospitals' benefits and dental benefits than in the other attributes. At 90\% cost coverage, the higher educated had a higher utility level of the private hospital benefits than the lower educated group $(\mathrm{OR}=$ 3.67 vs. 2.31). Nevertheless, the more educated group's utility level of the dental benefits was higher than the lower educated one $(\mathrm{OR}=2.01$ vs. 1.32$)$.

Preferences of household head: The heads of the households had more utility from the coverage of the costs. For example, at $90 \%$ cost coverage the households' heads had a higher utility of the public hospitals' benefits than the non-head households' utility ( $\mathrm{OR}=2.20$ vs. 1.87 ), while the heads of the households had a lower utility of the private hospitals' benefits than the non-head households ( $O R=2.40$ vs. 3.34 ).

At $70 \%$ cost coverage for the dental services, the nonheads category of households had a higher utility than the household heads category ( $\mathrm{OR}=1.71$ vs. 1.45 ), while both the head and non-head household groups had disutility from the rehabilitation and para-clinical services ( $O R=0.98$ vs. 0.93$)$. The disutilities from the premium for both groups $(\mathrm{OR}=0.96$ vs. 0.97) were almost equal (Table 6).

Preferences by income: The findings indicated a positive association between the utility of most of the attributes and the participants' monthly income. At $90 \%$ cost coverage, those with a monthly income of more than 40 million IRRs had the highest utility of the private hospitals' benefits $(\mathrm{OR}=3.69)$ than those in the other income categories. In contrast, while those with a monthly income of fewer or equal to 20 million IRRs had the highest utility of the public hospitals' benefits $(\mathrm{OR}=2.26)$. Again, those with a monthly income of fewer or equal to 20 million IRRs showed an increased likelihood of utility of the outpatient services from $\mathrm{OR}=1.21$ to $\mathrm{OR}=1.83$ with an increase in cost coverage from $70 \%$ to $90 \%$.

The disutilities from the para-clinical and rehabilitation services and the premium was almost equal for all the income groups. That is, the premium showed less sensitivity to the income of the individuals. The utilities of the participants in the low and middle-income groups at $70 \%$ cost coverage for the para-clinical and rehabilitation and the high-income people with the long-term care at the same level of cost coverage were statistically insignificant $(P>.05)$.

Preferences by health status: Both the healthy individuals and individuals with chronic diseases had higher utilities from public and private hospitals benefits (inpatient services) than the utilities obtained from the other attributes. The probability of utilities from the public inpatient services among the patient group $(\mathrm{OR}=2.12)$ and healthy group $(\mathrm{OR}=1.92)$ showed slight difference. However, the healthy group had a higher utility from the private inpatient services at $90 \%$ cost coverage than the patient group ( $\mathrm{OR}=3.03$ vs. 2.67 ). Both the healthy and patient groups had almost equal utility from the outpatient services $(\mathrm{OR}=1.82 \mathrm{vs}$. 1.72$)$, and rehabilitation and para-clinical services $(\mathrm{OR}=1.68$ vs. 1.58$)$, while the patient group had a higher utility from long-term care than the healthy group $(\mathrm{OR}=1.63$ vs. 1.21$)$.

\section{Discussion}

This study elicited the insured Iranians' preferences about the different attributes of health insurance plans in Iran. Our findings revealed an increase in utility related to the increase in cost coverage for all the attributes analyzed, and the highest utility from the private hospitals' benefits followed by the public hospitals' benefits, and outpatient benefits, respectively. The quality of private healthcare services in Iran is assumed to be better than public healthcare services. ${ }^{25}$ The utility of cost coverage of private inpatient services was higher than the public hospitals' services. However, the households' heads had a higher utility from the public hospital benefits. Others reported a higher utility of the less educated from the public hospital benefits and disutility of the higher premium. ${ }^{26}$ Also, the high expenditure of the households' heads was one of the main reasons for the lower utility from private hospital benefits. ${ }^{27}$ The utilization of private hospital services was also associated with a higher probability of incurring catastrophic health expenditures (CHEs). ${ }^{28}$

Others reported the likely more preferences to both the public and private providers than to one of the providers alone. ${ }^{8}$ The individuals' higher preferences to the private than to the public hospitals' benefits at the $90 \%$ cost coverage observed in our study may imply better quality services of the private providers. Also, the utility from the use of private services was higher among high-income households, and the high hospital admission rate in Iran might reflect the higher socioeconomic status of those individuals with the admission need. That is, 
Table 5. Health Insurance Attributes Preferences of Participants by Gender, Age, and Educational Level in Tehran, Iran; 2016

\begin{tabular}{|c|c|c|c|c|c|c|c|c|c|c|c|c|c|}
\hline \multirow{3}{*}{ Attributes } & \multirow{3}{*}{$\begin{array}{l}\text { Cost } \\
\text { Coverage }\end{array}$} & \multicolumn{4}{|l|}{ Gender } & \multicolumn{4}{|l|}{ Age Group (y) } & \multicolumn{4}{|c|}{ Educational Level } \\
\hline & & \multicolumn{2}{|l|}{ Male } & \multicolumn{2}{|l|}{ Female } & \multicolumn{2}{|l|}{41 And Younger } & \multicolumn{2}{|l|}{ Older Than 41} & \multicolumn{2}{|l|}{ Lower Educated } & \multicolumn{2}{|c|}{ Higher Educated } \\
\hline & & $\beta$ (SE) & OR & $\beta(\mathrm{SE})$ & OR & $\beta$ (SE) & OR & $\beta$ (SE) & OR & $\beta$ (SE) & OR & $\beta$ (SE) & OR \\
\hline Public hospitals benefits (base: $60 \%$ ) & $90 \%$ & $0.801(0.049)^{\mathrm{a}}$ & 2.228 & $0.594(0.053)^{\mathrm{a}}$ & 1.811 & $0.683(0.048)^{a}$ & 1.980 & $0.742(0.054)^{a}$ & 2.100 & $0.768(0.049)^{\mathrm{a}}$ & 2.155 & $0.634(0.054)^{\mathrm{a}}$ & 1.885 \\
\hline \multirow{2}{*}{ Private hospitals benefits (base: $50 \%$ ) } & $70 \%$ & $0.542(0.073)^{\mathrm{a}}$ & 1.719 & $0.633(0.078)^{\mathrm{a}}$ & 1.883 & $0.665(0.072)^{\mathrm{a}}$ & 1.944 & $0.489(0.080)^{\mathrm{a}}$ & 1.631 & $0.467(0.071)^{\mathrm{a}}$ & 1.595 & $0.752(0.081)^{\mathrm{a}}$ & 2.121 \\
\hline & $90 \%$ & $0.949(0.075)^{a}$ & 2.583 & $1.146(0.084)^{\mathrm{a}}$ & 3.146 & $1.145(0.076)^{\mathrm{a}}$ & 3.142 & $0.914(0.083)^{\mathrm{a}}$ & 2.494 & $0.838(0.075)^{\mathrm{a}}$ & 2.312 & $1.300(0.085)^{\mathrm{a}}$ & 3.669 \\
\hline Outpatient benefits (base: $50 \%$ ) & $90 \%$ & $0.571(0.073)^{\mathrm{a}}$ & 1.770 & $0.558(0.077)^{\mathrm{a}}$ & 1.747 & $0.674(0.070)^{\mathrm{a}}$ & 1.962 & $0.415(0.08)^{\mathrm{a}}$ & 1.514 & $0.537(0.071)^{\mathrm{b}}$ & 1.711 & $0.594(0.079)^{\mathrm{a}}$ & 1.811 \\
\hline Dental coverage (base: $40 \%$ ) & $70 \%$ & $0.414(0.106)^{\mathrm{a}}$ & 1.513 & $0.500(0.119)^{\mathrm{a}}$ & 1.649 & $0.575(0.107)^{a}$ & 1.777 & $0.289(0.119)^{c}$ & 1.335 & $0.281(0.105)^{\mathrm{a}}$ & 1.324 & $0.699(0.122)^{\mathrm{a}}$ & 2.012 \\
\hline \multirow{2}{*}{$\begin{array}{l}\text { Rehabilitation and para-clinical } \\
\text { benefits (base: } 50 \% \text { ) }\end{array}$} & $70 \%$ & $0.04(0.091)$ & 1.041 & $-0.148(0.100)$ & 0.862 & $-0.058(0.090)$ & 0.944 & $-0.017(0.102)$ & 0.983 & $-0.002(0.090)$ & 0.998 & $-0.118(0.102)$ & 0.889 \\
\hline & $90 \%$ & $0.491(0.081)^{\mathrm{a}}$ & 1.634 & $0.480(0.089)^{\mathrm{a}}$ & 1.616 & $0.469(0.081)^{\mathrm{a}}$ & 1.598 & $0.502(0.089)^{\mathrm{a}}$ & 1.652 & $0.406(0.081)^{\mathrm{a}}$ & 1.501 & $0.571(0.089)^{\mathrm{a}}$ & 1.770 \\
\hline \multirow{2}{*}{ Long-term care benefits (base: 50\%) } & $70 \%$ & $0.244(0.102)^{c}$ & 1.276 & $0.273(0.111)^{\mathrm{b}}$ & 1.314 & $0.121(0.100)$ & 1.129 & $0.474(0.115)^{\mathrm{a}}$ & 1.606 & $0.296(0.102)^{\mathrm{b}}$ & 1.344 & $0.23(0.112)^{c}$ & 1.259 \\
\hline & $90 \%$ & $0.377(0.105)^{\mathrm{a}}$ & 1.458 & $0.348(0.114)^{b}$ & 1.416 & $0.188(0.103)$ & 1.207 & $0.613(0.117)^{\mathrm{a}}$ & 1.846 & $0.389(0.104)^{\mathrm{a}}$ & 1.476 & $0.349(0.116)^{b}$ & 1.418 \\
\hline Medical devices benefits (base: $60 \%$ ) & $90 \%$ & $0.162(0.070)^{c}$ & 1.176 & $0.264(0.074)^{\mathrm{a}}$ & 1.302 & $0.235(0.067)^{\mathrm{a}}$ & 1.265 & $0.169(0.078)$ & 1.184 & $0.209(0.070)^{\mathrm{b}}$ & 1.232 & $0.209(0.075)^{b}$ & 1.232 \\
\hline Premium (per 10000 IRRs) & - & $-0.033(0.005)^{\mathrm{a}}$ & 0.968 & $-0.040(0.005)^{\mathrm{a}}$ & 0.961 & $-0.033(0.005)^{\mathrm{a}}$ & 0.968 & $-0.039(0.005)^{\mathrm{a}}$ & 0.962 & $-0.042(0.005)^{\mathrm{a}}$ & 0.959 & $-0.029(0.005)^{\mathrm{a}}$ & 0.971 \\
\hline Observations & & 5232 & & 4368 & & 5360 & & 4240 & & 5264 & & 4336 & \\
\hline McFadden's $\mathrm{R}^{2}$ & & 0.1907 & & 0.196 & & 0.192 & & 0.197 & & 0.185 & & 0.21 & \\
\hline Log likelihood & & -1467 & & -1216 & & -1501 & & -1180 & & -1486 & & -1186 & \\
\hline LR chi2 $\left(1^{2}\right)$ & & 691 & & 593 & & 713 & & 580 & & 675 & & 632 & \\
\hline Prob > chi2 & & $<0.001$ & & $<0.001$ & & $<0.001$ & & $<0.001$ & & $<0.001$ & & $<0.001$ & \\
\hline
\end{tabular}

Abbreviations: $\mathrm{SE}$, standard error; $\mathrm{OR}$, odds ratio.

${ }^{\mathrm{a}} P<.00,{ }^{\mathrm{b}} P<.01,{ }^{\mathrm{c}} P<.05$ 
Table 6. Health Insurance Atributes Preferences of Participants by Status in Household, Income, and Health in Tehran, Iran; 2016

\begin{tabular}{|c|c|c|c|c|c|c|c|c|c|c|c|c|c|c|c|}
\hline \multirow{3}{*}{ Attributes } & \multirow{3}{*}{$\begin{array}{l}\text { Cost } \\
\text { Coverage }\end{array}$} & \multicolumn{4}{|c|}{ Status in Household } & \multicolumn{6}{|c|}{ Household Income (Monthly) } & \multicolumn{4}{|l|}{ Health Status } \\
\hline & & \multicolumn{2}{|c|}{ Head of Household } & \multicolumn{2}{|c|}{ Non-head Household } & \multicolumn{2}{|c|}{$<20$ Million Rials } & \multicolumn{2}{|c|}{ 20-40 Million Rials } & \multicolumn{2}{|c|}{ > 40 Million Rials } & \multicolumn{2}{|l|}{$\begin{array}{l}\text { Have a Chronic } \\
\text { Condition(s) }\end{array}$} & \multicolumn{2}{|l|}{ Healthy } \\
\hline & & $\beta$ (SE) & OR & $\beta$ (SE) & OR & $\beta$ (SE) & OR & $\beta$ (SE) & OR & $\beta$ (SE) & OR & $\beta$ (SE) & OR & $\beta$ (SE) & OR \\
\hline Public hospitals benefits (base: 60\%) & $90 \%$ & $0.786(0.051)^{\mathrm{a}}$ & 2.195 & $0.627(0.051)^{\mathrm{a}}$ & 1.872 & $0.816(0.052)^{\mathrm{a}}$ & 2.261 & $0.628(0.064)^{\mathrm{a}}$ & 1.874 & $0.549(0.085)^{\mathrm{a}}$ & 1.732 & $0.749(0.049)^{a}$ & 2.115 & $0.653(0.053)^{\mathrm{a}}$ & 1.921 \\
\hline \multirow{2}{*}{$\begin{array}{l}\text { Private hospitals benefits (base: } \\
50 \% \text { ) }\end{array}$} & $70 \%$ & $0.487(0.075)^{\mathrm{a}}$ & 1.627 & $0.685(0.076)^{a}$ & 1.984 & $0.512(0.076)^{\mathrm{a}}$ & 1.669 & $0.643(0.093)^{a}$ & 1.902 & $0.764(0.132)^{\mathrm{a}}$ & 2.147 & $0.522(0.071)^{\mathrm{a}}$ & 1.685 & $0.67(0.081)^{\mathrm{a}}$ & 1.954 \\
\hline & $90 \%$ & $0.875(0.078)^{\mathrm{a}}$ & 2.399 & $1.207(0.081)^{\mathrm{a}}$ & 3.343 & $0.905(0.080)^{\mathrm{a}}$ & 2.472 & $1.145(0.099)^{c}$ & 3.142 & $1.307(0.133)^{\mathrm{a}}$ & 3.695 & $0.984(0.075)^{\mathrm{a}}$ & 2.675 & $1.11(0.084)^{\mathrm{a}}$ & 3.034 \\
\hline \multirow{2}{*}{ Outpatient benefits (base: $50 \%$ ) } & $70 \%$ & $0.344(0.071)^{\mathrm{a}}$ & 1.411 & $0.200(0.072)^{b}$ & 1.221 & $0.192(0.071)^{b}$ & 1.212 & $0.35(0.090)^{\mathrm{a}}$ & 1.419 & $0.401(0.124)^{a}$ & 1.493 & $0.259(0.067)^{\mathrm{a}}$ & 1.296 & $0.291(0.076)^{\mathrm{a}}$ & 1.338 \\
\hline & $90 \%$ & $0.552(0.076)^{\mathrm{a}}$ & 1.737 & $0.571(0.073)^{a}$ & 1.770 & $0.606(0.074)^{a}$ & 1.833 & $0.563(0.093)^{\mathrm{a}}$ & 1.756 & $0.46(0.129)^{\mathrm{a}}$ & 1.584 & $0.540(0.072)^{\mathrm{a}}$ & 1.716 & $0.596(0.077)^{\mathrm{a}}$ & 1.815 \\
\hline Dental coverage benefits (base: $40 \%$ ) & $70 \%$ & $0.368(0.111)^{b}$ & 1.445 & $0.539(0.113)^{\mathrm{a}}$ & 1.714 & $0.388(0.110)^{\mathrm{a}}$ & 1.474 & $0.399(0.142)^{b}$ & 1.490 & $0.781(0.201)^{\mathrm{a}}$ & 2.184 & $0.463(0.105)^{\mathrm{a}}$ & 1.589 & $0.438(0.12)^{\mathrm{a}}$ & 1.550 \\
\hline \multirow{2}{*}{$\begin{array}{l}\text { Rehabilitation and para-clinical } \\
\text { benefits (base: } 50 \% \text { ) }\end{array}$} & $70 \%$ & $-0.017(0.095)$ & 0.983 & $-0.077(0.096)$ & 0.926 & $-0.039(0.095)$ & 0.962 & $-0.070(0.119)$ & 0.932 & $-0.039(0.166)$ & 0.962 & $-0.062(0.091)$ & 0.940 & $-0.028(0.1)$ & 0.972 \\
\hline & $90 \%$ & $0.474(0.084)^{a}$ & 1.606 & $0.491(0.085)^{\mathrm{a}}$ & 1.634 & $0.458(0.085)^{\mathrm{a}}$ & 1.581 & $0.512(0.106)^{\mathrm{a}}$ & 1.669 & $0.538(0.14)^{b}$ & 1.713 & $0.458(0.081)^{\mathrm{a}}$ & 1.581 & $0.521(0.088)^{\mathrm{a}}$ & 1.684 \\
\hline Long-term care benefits (base: $50 \%$ ) & $90 \%$ & $0.446(0.109)^{\mathrm{a}}$ & 1.562 & $0.292(0.109)^{b}$ & 1.339 & $0.282(0.109)^{c}$ & 1.326 & $0.361(0.135)^{b}$ & 1.435 & $0.631(0.191)^{\mathrm{b}}$ & 1.879 & $0.489(0.104)^{\mathrm{a}}$ & 1.631 & $0.190(0.114)$ & 1.209 \\
\hline Medical devices benefits (base: $60 \%$ ) & $90 \%$ & $0.193(0.073)^{b}$ & 1.213 & $0.222(0.071)^{b}$ & 1.249 & $0.245(0.073)^{a}$ & 1.278 & $0.220(0.089)^{c}$ & 1.246 & $0.121(0.122)^{b}$ & 1.129 & $0.262(0.07)^{\mathrm{a}}$ & 1.300 & $0.136(0.074)$ & 1.146 \\
\hline Premium (per 10000 IRRs) & - & $-0.038(0.005)^{\mathrm{a}}$ & 0.963 & $-0.034(0.005)^{\mathrm{a}}$ & 0.967 & $-0.041(0.005)^{a}$ & 0.960 & $-0.037(0.006)^{a}$ & 0.964 & $-0.021(0.008)^{a}$ & 0.979 & $-0.039(0.005)^{a}$ & 0.962 & $-0.031(0.005)^{\mathrm{a}}$ & 0.969 \\
\hline Observations & & 193 & & 0.195 & & 4896 & & 3024 & & 1680 & & 5408 & & 4192 & \\
\hline McFadden's $\mathrm{R}^{2}$ & & -1342 & & -1338 & & 0.199 & & 0.195 & & 0.198 & & 0.195 & & 0.18 & \\
\hline Log likelihood & & 643 & & 649 & & -1358 & & -843 & & -466 & & -1496 & & -1191 & \\
\hline LR chi2 $\left(1^{2}\right)$ & & $<0.001$ & & $<0.001$ & & 679 & & 409 & & 231 & & 755 & & 522 & \\
\hline Prob > chi2 & & 2785 & & 2779 & & $<0.001$ & & $<0.001$ & & $<0.001$ & & $<0.001$ & & $<0.001$ & \\
\hline
\end{tabular}

Abbreviations: $\mathrm{SE}$, standard error; $\mathrm{OR}$, odds ratio.

${ }^{\mathrm{a}} P<.00,{ }^{\mathrm{b}} P<.01,{ }^{\mathrm{c}} P<.05$ 
people with higher socioeconomic status are likely to have better access to healthcare in general, and inpatient services in particular. The difference in health insurance coverage might be one of the main reasons for such variations. ${ }^{29}$ Thus, improving health insurance coverage increases the utilization of healthcare services. ${ }^{29-31}$ A study in Ethiopia also revealed peoples' preference for health insurance packages with access to both the public and private providers. ${ }^{32}$

Gender of the insured participants was one of the main factors which affected preference. At the highest level of cost coverage, the males' preference for public hospitals' benefits was considerably higher than that of the females,' while at the same rate of cost coverage, females had a markedly higher preference for the private hospitals' benefits than the males do. Nevertheless, the disutility of both genders from the premium was almost the same. Evidence revealed a higher preference of women for outpatient services and men for inpatient services. Like in ours, the disutility from the premium was the same for both men and women. ${ }^{26}$

The findings also revealed an age difference in utilities of the health insurance benefits. The younger individuals' utilities from the coverage of the private hospitals' benefits, outpatient and dental coverage benefits were higher than the utilities of the older ones. The impact of age on household choice for insurance is found to be non-linear and U-shaped. ${ }^{33}$ The older individuals in our findings revealed a higher utility from the long-term benefits than their counterpart, which might be due to the occurrence of aging-related chronic diseases. ${ }^{34}$ In Japan's public sector, the provision of mandatory long-term care insurance was in place since 2000 to ensure better accessibility of healthcare services to the elderly and reduce the healthcare-related burden on the families of the elderly. However, its sustainability was challenging because of financial constraints. ${ }^{35}$ The premium of the available small private market for long-term health insurance was also expensive compared to its benefits. ${ }^{36}$ Again, those who have more coverage were likely to frequently utilize more medical services than those with less coverage. ${ }^{37}$ Thus, income is one of the main factors which determine health insurance preference of health expenditures of people. ${ }^{38}$ Our findings indicated the odds of choosing health insurance with more cost coverage among the higher income groups, which is consistent with the findings which reported wealthier individuals are more likely to seek and prefer for the private than public medical services. $^{39}$

The findings indicated a higher utility from the dental services with higher cost coverage and the more preference for the dental care benefits insurance coverage among the more educated individuals. Similarly, a study in Namibia reported an association between educational status and health insurance, ${ }^{40}$ and an association between more dental healthcare services utilization and several factors including aging, having dental insurance, higher income, being a university graduate, self-rated poor oral health and not regularly brushing own teeth. ${ }^{41}$ In Iran, there are different sources for the insurance of the health benefits packages. ${ }^{42}$ Thus, the high complementary health insurance coverage (>35\%) observed in our findings might inform the uniform provision of social insurance benefits and the lack of diversity of the benefits packages to the citizens. This condition might have resulted from the influence of the individuals' decisions in purchasing the health insurance benefit packages by several factors including the demographic, socioeconomic and past health services utilization. ${ }^{14}$

The low utility from the rehabilitation and para-clinical services revealed in our findings might be related to the limited choices and low quality and quantity of the services available. ${ }^{43}$ These conditions, in turn, might have influenced the individuals' preferences, and the cost coverage of the services. Other DCE related studies in high and low-income countries reported that the benefits of the services and the extent of the cost coverage had marked influence on the individuals' choices..$^{27,44,45}$ The uncertainty of whether to utilize the healthcare services or not and the CHEs related to the utilization of the services can also influence the individuals' rationale decision in selecting the benefit packages. ${ }^{44}$ Our findings showed that the individuals' desire for full coverage of the health benefits package even to the services not included in the insurance benefit packages, and equal premium to all approach is a known source of dissatisfaction. ${ }^{46}$

Despite the insignificant relationship between the participants with chronic health conditions and their preferences to most of the attributes analyzed, there was a significantly higher preference for the long-term care benefit packages. Besides, those participants with chronic conditions were older than healthy individuals. The chronic health conditions are among the main factors which affect preferences. ${ }^{47,48}$ Individual's health status and purchasing of health insurance are inversely related and can, in turn, affect the health benefits packages utilization. Also, healthy individuals usually purchase more private health benefits packages insurances than public ones. Again, evidence shows that despite the complementary and voluntary benefits packages, health insurance purchasing may not be affected by an individual's health risks. ${ }^{49}$ In contrast, risk-averse individuals seek to get utility by purchasing health insurance to avoid the consequences of the risks. ${ }^{50} \mathrm{~A}$ person with poor health condition, especially among the self-employed, is more likely to experience financial problems and challenges to purchase health insurance. ${ }^{51}$ Thus, securing insurance for the health benefits packages from the public sector can help protect the poor against CHEs and improve health outcomes. ${ }^{52}$

This study attempted to investigate the health insurance preferences of insured people in Iran. The findings provided useful information for health policy-makers and HIOs to better understand and improve the design of the existing health insurance plans in the context. However, the analysis focused on conveniently obtained data of a limited geographic area. Thus, our findings necessitate cautious interpretations. With this assumption that previous evidence and experts can reflect the opinions of insured people about attributes of health insurance, we excluded them from the first phase of the study.

\section{Conclusion}

The findings revealed that the participants tended to 
choose health insurance plans with higher cost coverage for healthcare services and with lower premiums. However, the individuals' health insurance preferences were subject to the influences of the demographic characteristics, income, and health status. The findings are believed to contribute to the designing of better health insurance policies in the context of Iran, improve the participation of the citizens in health insurance, and increase the utility of the insured from the insurance benefits packages.

\section{Acknowledgments}

The authors would like to thank Prof. Arash Rashidian for his scientific suggestions in developing and designing this study. The authors would also like to thank Tehran University of Medical Sciences, Tehran, Iran (Fund No. 29725), and Social Security Research Institute, Tehran, Iran (Fund No. 395002684) for their financial support, and the SSIO and Iran $\mathrm{HIO}$ for their relentless cooperation in providing us with the needed data for the analysis.

\section{Ethical issues}

This study was approved by Ethics Committee for Tehran University of Medical Sciences, Tehran, Iran (9121504005).

\section{Competing interests}

Authors declare that they have no competing interests.

\section{Authors' contributions}

AKK and AAS were involved to designing the study. AKK was responsible for cleaning data and running statistical analysis and interpretation of the results. AKK and AW were responsible for writing the first draft. All authors contributed equally to editing draft versions and accept full responsibility for the content of the manuscript.

\section{Authors' affiliations}

${ }^{1}$ Research Center for Environmental Determinants of Health, Health Institute, Kermanshah University of Medical Sciences, Kermanshah, Iran. ${ }^{2}$ Department of Health Economics and Management, School of Public Health, Tehran University of Medical Sciences, Tehran, Iran. ${ }^{3}$ School of Public Health, College of Health Sciences, Mekelle University, Tigray, Ethiopia.

\section{References}

1. World Health Organization (WHO). The world health report: health systems financing: the path to universal coverage (Arabic). Geneva: WHO; 2010.

2. Asgary A, Willis $K$, Taghvaei AA, Rafeian M. Estimating rural households' willingness to pay for health insurance. Eur J Health Econ. 2004;5(3):209-215. doi:10.1007/s10198-004-0233-6

3. Davari M, Haycox A, Walley T. The Iranian health insurance system; past experiences, present challenges and future strategies. Iran $J$ Public Health. 2012;41(9):1-9.

4. World Bank, World Bank Data. Rural population (\% of total population). https://data.worldbank.org/indicator/SP.RUR.TOTL. ZS?locations=IR.5.

5. Reports of health insurance organization. http://ihio.gov.ir. Accessed February 29, 2019.

6. Abolhallaje M, Ramezanian $M$, Abolhasani $N$, Salarianzadeh $H$, Hamidi H, Bastani P. Iranian health financing system: challenges and opportunities. World Appl Sci J. 2013;22(5):662-666. doi:10.5829/ idosi.wasj.2013.22.05.71247

7. van den Berg $B$, Van Dommelen $P$, Stam $P$, Laske-Aldershof T, Buchmueller T, Schut FT. Preferences and choices for care and health insurance. Soc Sci Med. 2008;66(12):2448-2459. doi:10.1016/j.socscimed.2008.02.021

8. Nanna A. Health insurance in developing countries: willingness to pay for health insurance in Thailand using discrete choice experiment methods. Curtin University; 2011.
9. Kananurak P. An economic analysis of voluntary health insurance after retirement [dissertation]. Thailand: National Institute of Development Administration; 2013.

10. Brau R, Lippi Bruni M. Eliciting the demand for long-term care coverage: a discrete choice modelling analysis. Health Econ. 2008;17(3):411-433. doi:10.1002/hec.1271

11. World Health Organization (WHO). Middle Eastern Region: Iran (Islamic Republic of) statistics summary. https://www.who.int/ countries/irn/en/. Accessed February 27, 2019.

12. Shadpour K. Primary health care networks in the Islamic Republic of Iran. East Mediterr Health J. 2000;6(4):822-825.

13. Mehrdad R. Health system in Iran. Journal of International Medical Community. 2009;52(1):69-73.

14. Nosratnejad S, Rashidian A, Mehrara M, Jafari N, Moeini M, Babamohammadi $\mathrm{H}$. Factors influencing basic and complementary health insurance purchasing decisions in Iran: Analysis of data from a national survey. World Med Health Policy. 2016;8(2):179-196. doi:10.1002/wmh3.187

15. Moradi-Lakeh M, Vosoogh-Moghaddam A. Health sector evolution plan in Iran; equity and sustainability concerns. Int J Health Policy Manag. 2015;4(10):637-640. doi:10.15171/ijhpm.2015.160

16. Nosratnejad S, Rashidian A, Mehrara M, Akbari Sari A, Mahdavi G, Moeini M. Willingness to pay for the social health insurance in Iran. Glob J Health Sci. 2014;6(5):154-163. doi:10.5539/gjhs.v6n5p154

17. Ryan M, Kolstad JR, Rockers PC, Dolea C. How to conduct a discrete choice experiment for health workforce recruitment and retention in remote and rural areas: a user guide with case studies. World Health Organization, CapacityPlus, World Bank; 2012.

18. Ryan M, Scott DA, Reeves C, et al. Eliciting public preferences for healthcare: a systematic review of techniques. Health Technol Assess. 2001;5(5):1-186.

19. Louviere JJ, Hensher DA, Swait JD. Stated Choice Methods: Analysis and Application. Cambridge University Press; 2000.

20. Kazemi Karyani A, Rashidian A, Akbari Sari A, Emamgholipour Sefiddashti S. Developing attributes and levels for a discrete choice experiment on basic health insurance in Iran. Med J Islam Repub Iran. 2018;32:26. doi:10.14196/mjiri.32.26

21. Orme BK. Getting started with conjoint analysis: strategies for product design and pricing research. Madison: Research Publishers LLC; 2006.

22. Hauber AB, Gonzalez JM, Groothuis-Oudshoorn CG, et al. Statistical methods for the analysis of discrete choice experiments: a report of the ISPOR Conjoint Analysis Good Research Practices Task Force. Value Health. 2016;19(4):300-315. doi:10.1016/j.jval.2016.04.004

23. McFadden D. Conditional logit analysis of qualitative choice behavior. Berkeley: University of California; 1973.

24. Cushing $\mathrm{C}$, Cushing B. Conditional logit, IIA, and alternatives for estimating models of interstate migration. Annual Meeting of the Southern Regional Science Association; Charleston, SC; 2007.

25. Rezaei S, Hajizadeh M, Zandian H, Fathi A, Nouri B. Service quality in Iranian hospitals: A systematic review and meta-analysis. Med J Islam Repub Iran. 2018;32:59. doi:10.14196/mjiri.32.59

26. Kananurak P. Willingness to Pay for Voluntary Health Insurance after Retirement in Thailand. NIDA Development Journal. 2014;54(2):117-157. doi:10.14456/ndj.2014.19

27. Hershey JC, Kunreuther H, Schwartz JS, Williams SV. Health insurance under competition: would people choose what is expected? Inquiry. 1984;21(4):349-360.

28. Hajizadeh M, Nghiem HS. Out-of-pocket expenditures for hospital care in Iran: who is at risk of incurring catastrophic payments? Int J Health Care Finance Econ. 2011;11(4):267-285. doi:10.1007/ s10754-011-9099-1

29. Etemad $K$, Yavari $P$, Mehrabi $Y$, et al. Inequality in utilization of in-patients health services in Iran. Int J Prev Med. 2015;6:45. doi:10.4103/2008-7802.158169

30. Yip W, Berman P. Targeted health insurance in a low income country and its impact on access and equity in access: Egypt's school health insurance. Health Econ. 2001;10(3):207-220. doi:10.1002/hec.589

31. Liu GG, Zhao Z, Cai R, Yamada T, Yamada T. Equity in health care access to: assessing the urban health insurance reform in China. Soc Sci Med. 2002;55(10):1779-1794.

32. Obse A, Ryan M, Heidenreich S, Normand C, Hailemariam D. 
Eliciting preferences for social health insurance in Ethiopia: a discrete choice experiment. Health Policy Plan. 2016;31(10):14231432. doi:10.1093/heapol/czw084

33. Kumar A. Investigating household choice for health and life insurance. Appl Econ Lett. 2019;26(4):267-273. doi:10.1080/1350 4851.2018.1467543

34. Haseen F, Adhikari R, Soonthorndhada K. Self-assessed health among Thai elderly. BMC Geriatr. 2010;10(1):1-9. doi:10.1186/14712318-10-30

35. Tamiya N, Noguchi $H$, Nishi A, et al. Population ageing and wellbeing: lessons from Japan's long-term care insurance policy. Lancet. 2011;378(9797):1183-1192. doi:10.1016/s0140-6736(11)61176-8

36. Brown JR, Finkelstein $A$. Why is the market for long-term care insurance so small? J Public Econ. 2007;91(10):1967-1991. doi:10.1016/j.jpubeco.2007.02.010

37. Hurd MD, McGarry K. Medical insurance and the use of health care services by the elderly. J Health Econ. 1997;16(2):129-154.

38. Jowett M, Contoyannis P, Vinh ND. The impact of public voluntary health insurance on private health expenditures in Vietnam. Soc Sci Med. 2003;56(2):333-342.

39. Kermani MS, Ghaderi H, Yousefi A. Demand for medical care in the urban areas of Iran: an empirical investigation. Health Econ. 2008;17(7):849-862. doi:10.1002/hec.1308

40. Allcock SH, Young EH, Sandhu MS. Sociodemographic patterns of health insurance coverage in Namibia. Int $J$ Equity Health. 2019;18(1):16. doi:10.1186/s12939-019-0915-4

41. Rezaei S, Woldemichael A, Zandian H, Homaie Rad E, Veisi N, Karami Matin B. Dental health-care service utilisation and its determinants in West Iran: a cross-sectional study. Int Dent J. 2018;68(3):176-182. doi:10.1111/idj.12346

42. Kerssens JJ, Groenewegen PP. Consumer preferences in social health insurance. Eur J Health Econ. 2005;6(1):8-15. doi:10.1007/ s10198-004-0252-3

43. Ahmadzadeh N, Ebadi Fard Azar F, Baradaran HR, et al. Availability of outpatient rehabilitation facilities in 2015 in Iran: A nationwide study. Med J Islam Repub Iran. 2018;32:123. doi:10.14196/ mjiri.32.123

44. Abiiro GA, Torbica A, Kwalamasa K, De Allegri M. Eliciting community preferences for complementary micro health insurance: a discrete choice experiment in rural Malawi. Soc Sci Med. 2014;120:160-168. doi:10.1016/j.socscimed.2014.09.021

45. Booske BC, Sainfort F, Hundt AS. Eliciting consumer preferences for health plans. Health Serv Res. 1999;34(4):839-854.

46. Kerssens JJ, Groenewegen PP. Consumer choice of social health insurance in managed competition. Health Expect. 2003;6(4):312322. doi:10.1046/j.1369-7625.2003.00229.x

47. Glazer J, McGuire TG. Optimal risk adjustment in markets with adverse selection: an application to managed care. Am Econ Rev. 2000;90(4):1055-1071.

48. Rothschild $M$, Stiglitz J. Equilibrium in competitive insurance markets: An essay on the economics of imperfect information. $Q J$ Econ. 1976;90(4):629-649. doi:10.2307/1885326

49. Buchmueller TC, Monheit AC. Employer-sponsored health insurance and the promise of health insurance reform. Inquiry. 2009;46(2):187202. doi:10.5034/inquiryjrnl 46.02 .187

50. Nyman JA. The value of health insurance. Chapters; 2006.

51. Hajizadeh M, Connelly L, Butler JRG, Khosravi A. Unmet need and met unneed in health care utilisation in Iran. Int $J$ Soc Econ. 2012;39(6):400-422.

52. World Health Organization (WHO). Designing health financing systems to reduce catastrophic health expenditure. Geneva: WHO; 2005. 